\title{
On the measurement of rumination: a psychometric evaluation of the ruminative response scale and the rumination on sadness scale in undergraduates.
}

Citation for published version (APA):

Roelofs, J., Muris, P. E. H. M., Huibers, M. J. H., Peeters, F. P. M. L., \& Arntz, A. R. (2006). On the measurement of rumination: a psychometric evaluation of the ruminative response scale and the rumination on sadness scale in undergraduates. Journal of Behavior Therapy and Experimental Psychiatry, 37(4), 299-313. https://doi.org/10.1016/j.jbtep.2006.03.002

Document status and date:

Published: 01/01/2006

DOI:

10.1016/j.jbtep.2006.03.002

Document Version:

Publisher's PDF, also known as Version of record

\section{Document license:}

Taverne

Please check the document version of this publication:

- A submitted manuscript is the version of the article upon submission and before peer-review. There can be important differences between the submitted version and the official published version of record.

People interested in the research are advised to contact the author for the final version of the publication, or visit the DOI to the publisher's website.

- The final author version and the galley proof are versions of the publication after peer review.

- The final published version features the final layout of the paper including the volume, issue and page numbers.

Link to publication

\footnotetext{
General rights rights.

- You may freely distribute the URL identifying the publication in the public portal. please follow below link for the End User Agreement:

www.umlib.nl/taverne-license

Take down policy

If you believe that this document breaches copyright please contact us at:

repository@maastrichtuniversity.nl

providing details and we will investigate your claim.
}

Copyright and moral rights for the publications made accessible in the public portal are retained by the authors and/or other copyright owners and it is a condition of accessing publications that users recognise and abide by the legal requirements associated with these

- Users may download and print one copy of any publication from the public portal for the purpose of private study or research.

- You may not further distribute the material or use it for any profit-making activity or commercial gain

If the publication is distributed under the terms of Article 25fa of the Dutch Copyright Act, indicated by the "Taverne" license above, 


\title{
On the measurement of rumination: A psychometric evaluation of the ruminative response scale and the rumination on sadness scale in undergraduates
}

\author{
Jeffrey Roelofs ${ }^{\mathrm{a}, *}$, Peter Muris ${ }^{\mathrm{b}}$, Marcus Huibers ${ }^{\mathrm{a}}$, \\ Frenk Peeters ${ }^{\mathrm{c}}$, Arnoud Arntz ${ }^{\mathrm{a}}$ \\ a Department of Medical, Clinical, and Experimental Psychology, Maastricht University, P.O. Box 616, \\ 6200 MD Maastricht, The Netherlands \\ ${ }^{\mathrm{b}}$ Institute of Psychology, Erasmus University Rotterdam, The Netherlands \\ ${ }^{\mathrm{c}}$ Department of Psychiatry, University Hospital Maastricht, The Netherlands
}

Accepted 8 November 2005

\begin{abstract}
Rumination is considered a specific cognitive vulnerability factor that is thought to play a prominent role in the maintenance of depressive symptoms. The present study investigated the psychometric properties of two measures of rumination, the ruminative response scale (RRS) and the rumination on sadness scale (RSS) in undergraduates $(N=331)$. A joint factor analysis yielded three factors, 'rumination on causes of sadness', 'symptom-based rumination', and 'rumination on sadness'. The internal consistency of the rumination factors was good and the test-retest stability over a 6-month period of time was moderate. Support was also found for the construct validity of the rumination factors. Finally, the 'rumination on the causes of sadness' factor was found to moderate the relation between depression measured at baseline and at 6-month follow-up. More specifically, baseline depression was a strong predictor of future depression but this was particularly true for high ruminating individuals. Implications of the results and directions for future research are provided. (C) 2006 Elsevier Ltd. All rights reserved.
\end{abstract}

Keywords: Rumination; Depression; Self-report questionnaires; Psychometric properties

\footnotetext{
*Corresponding author. Tel.: + 31433881607.

E-mail address: J.Roelofs@dep.unimaas.nl (J. Roelofs).
} 


\section{Introduction}

Mood regulation strategies refer to thoughts and behaviors intended to maintain, change, or eliminate emotional states (Rusting \& Nolen-Hoeksema, 1998). Coping strategies can be applied to regulate mood by acting externally on the world (problemfocused coping) or acting internally to change beliefs or attention (emotion-focused coping). Depression has been associated with excessive use of emotion-focused coping strategies, in particular rumination (Nolen-Hoeksema, 1998). Ruminative responses involve a pattern of behaviors and thoughts that focus one's attention on depressive symptoms and the implications and consequences of these symptoms for the individual in order to gain insight (Nolen-Hoeksema, 1991). The response styles theory was originally developed to account for gender differences in responding to negative mood (e.g., depression), with women being more likely to engage in ruminative responses thereby amplifying their symptoms and extending the depressive episode, and men being likely to distract themselves from depressed mood, thereby dampening their symptoms (NolenHoeksema, 1987, 1990, 1991; Nolen-Hoeksema, Larson, \& Grayson, 1999). Meanwhile, it is generally accepted that individual differences in ruminative responses to negative mood may account for differences in duration and severity of these moods (e.g., Teasdale \& Dent, 1987).

Rumination can be conceptualized as a dimensional construct allowing for examination in clinical as well as non-clinical samples. Several longitudinal, correlational, and experimental studies conducted in clinical and non-clinical populations have supported the proposition of the response styles theory that a ruminative response style may not only predict the onset of depressive symptoms but may also be predictive of longer duration and more severe depressive symptoms (e.g., Just \& Alloy, 1997; Lyubomirsky \& NolenHoeksema, 1993; Nolen-Hoeksema, 1991, 1997; Nolen-Hoeksema \& Morrow, 1991, 1993; Nolen-Hoeksema, Morrow, \& Frederickson, 1993; Nolen-Hoeksema, Parker \& Larson, 1994). Empirical support for the mood-improving effects of distraction is less convincing (e.g., Lam, Schuck, Smith, Farmer, \& Checkley, 2003; Kuehner \& Weber, 1999; NolenHoeksema \& Morrow, 1993). The ambiguous effects of distraction on the relieve of depressive mood can be explained by Wegner's theory, which posits that suppressing thoughts via distraction may increase, rather than decrease, the severity of emotional symptoms (Muris, Merckelbach, \& De Jong, 1993; Wegner, 1994; see also Wegner, Schneider, Carter, \& White, 1987).

The measurement of rumination as conceptualized by Nolen-Hoeksema and co-workers was advanced by the development of the ruminative response scale (RRS), which is a subscale of the response styles questionnaire (RSQ; Nolen-Hoeksema \& Morrow, 1991). The RRS consists of 22 items that assess responses to dysphoric mood that are focused on the self, on symptoms, and on possible causes and consequences of moods. Over the years, the RRS has undergone some changes but the different forms are highly similar. Several studies have addressed the factor structure and the psychometric properties of the RRS. To begin with, Roberts, Gilboa, and Gotlib (1998) conducted an exploratory factor analysis on RRS scores of 299 undergraduates and retained a three-factor model of which the factors were labeled 'symptom-based rumination', 'introspection and self-isolation', and 'self-blame'. In the same study, a confirmatory factor analysis showed an adequate fit for this three-factor model in a second sample of 317 undergraduates. 
The psychometric properties of the RRS have also been investigated in clinical samples. For example, Lam, Smith, Checkley, Rijsdijk, and Sham (2003) conducted an exploratory factor analysis on RRS scores of 109 depressed outpatients and obtained a four-factor model of which the first three factors closely resembled the factor structure found by Roberts et al. (1998). The fourth factor was labeled 'analyze to understand' but this factor did not show a significant association with self-reported severity of depression symptoms. It should be noted that in both studies, only 15 items were retained in the final factor solutions, as the remaining items did not show a substantial loading on any of the factors. Furthermore, an exploration of the reliability and validity of the subscales was not a central issue in these studies. Bagby and Parker (2001) conducted an exploratory factor analysis on RSQ scores of 168 depressed outpatients and retained two rumination factors in addition to one distraction factor. The rumination factors were labeled 'symptomfocused rumination' and 'self-focused rumination'. The internal consistency coefficients of the symptom-focused rumination factor and self-focused rumination scale were adequate ( $\alpha=.76$ and $\alpha=.77$, respectively). Surprisingly, both subscales failed to demonstrate an association with symptom variables (i.e., duration of current depressive episode and number of previous depressive episodes) or treatment variables (i.e., treatment outcome and decrease in depressive symptoms). An exploratory factor analysis by Cox, Enns, and Taylor (2001) of RRS scores of 142 depressed outpatients yielded an almost identical factor structure compared to Bagby and Parker (2001).

Some authors have expressed concerns about the content overlap of items of the RRS with items of measures of depression such as the BDI (see Conway, Csank, Holm, \& Blake, 2000; Treynor, Gonzalez \& Nolen-Hoeksema, 2003). Treynor et al. (2003) dealt with the overlap by constructing a new rumination measure by selecting items of the RRS that did not show overlap with items of the BDI. An exploratory factor analysis indicated that this measure comprised two factors of which the first factor was labeled 'reflection' and the second factor 'brooding'. Treynor et al. (2003) reported adequate internal consistency and test-retest stability ( 1 year time interval) for the reflection subscale $(\alpha=.72$ and $r=.60$, respectively) and the brooding subscale and ( $\alpha=.79$ and $r=.62$, respectively). Further, it was found that both reflection and brooding were associated with high concurrent levels of depression. Over time, however, brooding was related to higher levels of depression, whereas reflection was linked to lower levels of depression. These results suggest that in the long run, reflection may be more adaptive as it may possibly lead to effective problem solving (Treynor et al., 2003).

The content overlap of RRS items with items of the BDI led Conway et al. (2000) to the development of the RSS, a new measure of rumination as an alternative to the RRS. Items were derived with the goal of assessing various aspects of rumination specifically related to sadness and distress. The RSS contains 13 items and an exploratory factor analysis has shown that these items comprise one factor. Conway et al. (2000) reported good internal consistency of the RSS $(\alpha=.91)$ and adequate test-retest stability over a 2 - to 3-week period $(r=.70)$. The convergent and discriminant validity of the scale was supported using a large battery of questionnaires.

Taken together, the RRS is well supported by a theoretical model and a number of empirical studies. The RSS is a relatively new instrument assessing depressive rumination. It remains to be determined how the RSS relates to the RRS. As rumination may be a multi-component process, there is a need for studies that examine convergence and divergence in multiple self-report measures of rumination (see Siegle, 2000). This way, an 
increased specificity in the prediction of the maintenance of depressive symptoms over time can be obtained. The present study sought to examine the extent to which the RRS and RSS represent similar or different aspects of rumination. First, a joint (exploratory) factor analysis was conducted in which all RRS and RSS items were included. If the RRS and RSS reflect different aspects of rumination, then RRS items and RSS items should load on their corresponding RRS factor(s) and RSS factor(s) respectively. Second, reliability (i.e., internal consistency and test-retest stability) of the retained factors was assessed as well as their construct validity by comparing them to scores on related (i.e., depression, trait anxiety, neuroticism) and unrelated measures (i.e., fear of spiders, aggression). In line with the prediction of Conway et al. (2000), RSS factor(s) should show weaker associations with depressive symptoms compared to RRS factor(s). Finally, in accordance with the response styles theory, which considers rumination as a good candidate to predict the maintenance of depressive symptoms over time, we explored the extent to which the obtained rumination factors in interaction with baseline depression, predicted depression scores at 6 months follow-up. We hypothesized rumination to moderate the relation between baseline depression and future depression scores, such that baseline depression would be a strong predictor of future depression scores, especially in high ruminating individuals.

\section{Method}

\subsection{Participants}

A total number of 192 undergraduates (150 females) of Maastricht University participated in this study. Mean age of the sample was 21.1 years $(\mathrm{SD}=2.6)$. During the Spring of 2003, all 192 participants completed the RRS and RSS as well as an additional set of questionnaires (see below). From these 192 undergraduates, 73 individuals (61 females) participated in an experimental pain induction study 6 months later (see Roelofs, Peters, Deutz, Spijker, \& Vlaeyen, 2005) and were requested to complete a set of questionnaires, including the RRS and RSS. For the purpose of the factor analysis, another 140 undergraduates (108 females) of Maastricht University completed the RRS and RSS during the Spring of 2005. Mean age of this sample was 22.0 years $(\mathrm{SD}=2.5)$. No exact information about participants' ethnicity was available but the vast majority of the individuals were Caucasian (more than 95\%). Participants received some candy in turn for their participation.

\subsection{Measures}

\subsubsection{Rumination}

The ruminative response scale (RRS; Nolen-Hoeksema \& Morrow, 1991; Dutch version: Raes, Hermans, \& Eelen, 2003) includes 22 items describing responses to depressed mood that are self-focused, symptom-focused, and focused on the possible causes and consequences of dysphoric mood. Each item is rated on a Likert scale ranging from 1 (almost never) to 4 (almost always). The rumination on sadness scale (RSS; Conway et al., 2000; Dutch version: Raes et al., 2003) is a 13-item self-report measure of rumination of sadness. Respondents indicate the extent to which each item reflects their responses to sadness on a 5-point Likert scale ranging from 1 (not at all) to 5 (very much). The RRS and 
RSS are both reliable and valid measures of rumination (see for an overview Luminet, 2004).

\subsubsection{Neuroticism}

Neuroticism was measured with a subscale of the shortened and revised Eysenck personality questionnaire (EPQ; Eysenck \& Eysenck, 1991), which consists of 12 dichotomous items ('yes' or 'no'). Reliability and validity of the neuroticism scale of the EPQ is supported (e.g., Eysenck \& Eysenck, 1991).

\subsubsection{Depression}

The Zung depression scale (Zung, 1965) is a 20-item inventory of depression. Items are rated on a 4-point Likert scale ranging from 1 (none or a little bit of the time) to 4 (most or all of the time). The Zung is a reliable and valid measure of depression (e.g., Kozeny, 1987).

\subsubsection{Trait anxiety}

The trait version of the state-trait anxiety inventory (STAI-T; Spielberger, Gorsuch, \& Lushene, 1970) is a self-report measure of trait anxiety containing 20 items rated on a 4-point Likert scale ranging from 1 (almost never) to 4 (almost always). Reliability and validity have been well documented (e.g., Spielberger et al., 1970).

\subsubsection{Fear of spiders}

The fear of spiders questionnaire (FSQ; Szymanski \& O'Donohue, 1995) is an 18-item self-report measure of specific anxiety related to spiders. Items are rated on an 8-point scale ranging between 0 (fully agree) to 7 (fully disagree). Reliability and validity of the FSQ are good (Muris \& Merckelbach, 1996; Szymanski \& O’Donohue, 1995).

\subsubsection{Aggression}

The aggression questionnaire (AQ; Buss \& Perry, 1992) comprises 29 items scored on a 5-point Likert scale ranging from 1 (extremely like me) to 5 (extremely unlike me). Reliability and validity of the AQ have been well documented (Buss \& Perry, 1992; Meesters, Muris, Bosma, Schouten, \& Beuving, 1996).

For all questionnaires, higher scores reflect higher levels of the underlying (person) characteristic that the questionnaire presumes to measure.

\subsection{Procedure}

At baseline $(t=1)$, all participants completed a set of questionnaires in a fixed order, including the RRS, RSS, Zung, STAI-T, EPQ, FSQ, and the AQ. Participants completed the measures in a conference room in groups of five to ten students. A research assistant was always available to provide assistance and to ensure confidential and independent responding. Six months later $(t=2), 73$ participants completed the RRS, RSS, Zung, STAI-T, and the EPQ. The questionnaires administered at $t=2$ were completed individually in our laboratory in sound-attenuated rooms. The procedure for the additional participants for the factor analysis was similar to that followed at the $t=1$ assessment. These subjects completed the RRS and RSS in small group session under the supervision of a research assistant. 


\subsection{Statistical analyses}

\subsubsection{Factor structure}

A joint factor analysis was conducted in which scores on items of the RRS and the RSS of were subjected to a principal components analysis with an oblique (i.e., direct oblimin) rotation. Oblique rotation seemed most appropriate as this method allows the obtained factors to be intercorrelated. Parallel analysis was used to determine the number of factors to retain. Factor loadings $>.40$ were interpreted.

\subsubsection{Reliability}

Reliability of the rumination factors was examined by assessing internal consistency by means of Cronbach $\alpha$ and test-retest stability by computing intraclass correlation coefficients (ICC) over the 6-month time interval.

\subsubsection{Construct validity}

The construct validity of the obtained rumination factors was examined by computing Pearson correlation coefficients with related and unrelated measures $(t=1)$. The degree to which the strength of association between each of the expected rumination factors and selfreported depression (Zung), trait anxiety (STAI-T), and neuroticism (EPQ) differed was tested by means of $Z$-tests (see Cohen \& Cohen, 1983), that allow for a comparison of two correlated correlation coefficients with a variable in common based on the same sample. No substantial correlation coefficients were expected between the rumination factors and either FSQ or aggression AQ. To control for increased type I error due to multiple testing, $\alpha$ was set at .01.

\subsubsection{Prediction of depressive symptoms}

The influence of rumination as reflected by the retained factors at baseline $(t=1)$ on the maintenance of symptoms of depression at 6 months follow-up $(t=2)$ was assessed by means of linear regression analyses. A stepwise regression analysis was conducted in which rumination scores were entered on the first step, controlling for baseline depression and gender. On the second step, the interaction between baseline depression and rumination was entered. $\alpha$ was set at .05 for this analysis.

\section{Results}

\subsection{Joint factor analysis on items of the RRS and RSS}

Before addressing the main results, it should be noted that there were no differences on mean rumination scores between the 192 participants who completed the RRS and RSS at $t=1$, and the 140 additional undergraduates who filled out these measures some 2 years later. Consequently, the data from these samples were combined. One individual had too many missings $(>10 \%)$ and was dropped from the analyses, leaving a total number of 331 individuals for the factor analysis, descriptive statistics, and the assessment of the internal consistency reliability. Parallel analysis is a state-of-the-art and highly recommended procedure for determining the number of factors to retain in an exploratory factor analysis (see Zwick \& Velicer, 1986). In short, parallel analysis involves the extraction of eigenvalues from random data sets that parallel the actual data set with regard to the 
number of cases and variables. We used the SPSS-based parallel analysis program of O'Connor (2000). The first five randomly generated eigenvalues that correspond to the 95th percentile of the distribution of random data eigenvalues obtained with 100 replications were 1.76, 1.65, 1.57, 1.52, and 1.47. Parallel analysis assumes a normal distribution of the items. Most items were normally distributed as indexed by the skewness and kurtosis (range between -1 and +1 ), except for items 7 and 11 of the RRS and item 8 of the RSS, which were positively skewed. Therefore, polychoric correlations (i.e., correlations that do not assume a normal distribution) were computed by LISREL 8.30 (PRELIS) and were used as input for the exploratory factor analysis. The first five eigenvalues that were generated by the exploratory factor analyses were 15.11, 2.33, 1.92, 1.46, and 1.28. It is clear that the first three eigenvalues from the actual data are larger than the corresponding first three 95th percentile random data eigenvalue. This indicates that three factors should be retained.

The three rotated factors accounted for $43.1 \%, 6.7 \%$, and $5.5 \%$ of the variance respectively and the communalities ranged between .33 and .71 . The first factor consisted of both RRS and RSS items and was labeled 'rumination on causes of sadness'. It should be noted that the context in which rumination on causes of sadness occurs is either alone (e.g., self-isolation) or unspecified. The second factor was referred to as 'symptom-based rumination', which consisted mainly of RRS items. The third factor was labeled 'rumination on sadness' and comprised mainly of RSS items. Table 1 presents the factor loadings (i.e., pattern coefficients) of all items. Each item loaded uniquely on their corresponding factor, except for items 12 and 20 of the RRS, which had loadings just below the predefined criterion of .40 . There were a few items with secondary loadings (i.e., items 1, 3, and 11 of the RSS and item 13 of the RRS). The three factors were substantially intercorrelated (Pearson $r$ 's ranged between $=.68$ and .80 ). The correlations corrected for attenuation ranged between .86 and .88 indicating that the factors are distinct.

Table 2 presents descriptive statistics of the rumination scales and the other measures used in the present study. Total scores on the rumination scales were calculated by summing scores of individual items that loaded on the corresponding factor. Three remarks with respect to the descriptive data should be made. First, no differences were observed between rumination scores on baseline and at 6 months follow up. Second, baseline scores of the rumination scales from individuals who participated at $t=2$ did not differ from scores of the total sample at $t=1$. Finally, no significant gender differences were observed for the rumination scales and the other questionnaire's scores except for the FSQ, with females displaying higher fear of spider levels than males $[F(1,191)=10.5$, $\left.p=.001, \eta^{2}=.05\right]$.

In two additional analyses, scores on the RRS and RSS were factor analyzed separately. The procedure for these analyses was similar to that of the joint factor analysis (factor loadings not shown). For the RRS, the first three eigenvalues generated by means of parallel analysis were $1.58,1.47$, and 1.40 . The first three eigenvalues that were generated by the exploratory factor analysis were $8.01,1.73$, and 1.21, suggesting two RRS factors. The two RRS factors closely resembled the 'rumination on causes of sadness' (i.e., items 6 , $9,10,11,17,18,20,21$, and 22) and the 'symptom-based rumination' (i.e., items 1, 2, 3, 4, $5,7,8,12,13,14,15,16$, and 19) scales obtained in the joint factor analysis and accounted for $44 \%$ of the variance. For the RSS, the first two eigenvalues generated by means of parallel analysis were 1.42 and 1.31. The first two eigenvalues generated by the exploratory factor analysis were 6.28 and 1.17, suggesting a one-factor solution. All items loaded on 
Table 1

Factor structure obtained from a joint factor analysis of the RRS and the RSS items $(N=331)$

\begin{tabular}{|c|c|c|c|c|}
\hline Item & Item description & Factor 1 & Factor 2 & Factor 3 \\
\hline RRS 18. & $\begin{array}{l}\text { Go someplace alone to think about } \\
\text { my feelings }\end{array}$ & .76 & .03 & .03 \\
\hline RRS 10. & $\begin{array}{l}\text { Go away by yourself and think about } \\
\text { why you feel this way }\end{array}$ & .74 & .21 & .18 \\
\hline RRS 6. & $\begin{array}{l}\text { Analyze recent events to try to } \\
\text { understand why I am depressed }\end{array}$ & .72 & .22 & .09 \\
\hline RRS 21. & $\begin{array}{l}\text { Isolate yourself and think about the } \\
\text { reasons why I feel sad }\end{array}$ & .72 & .26 & .06 \\
\hline RSS 2. & $\begin{array}{l}\text { Repeatedly analyze and keep thinking } \\
\text { about reasons for sadness }\end{array}$ & .70 & .04 & .16 \\
\hline RRS 17. & $\begin{array}{l}\text { Analyze my personality to try to } \\
\text { understand why I am depressed }\end{array}$ & .68 & .13 & .16 \\
\hline RRS 22. & $\begin{array}{l}\text { Try to understand yourself by } \\
\text { focusing on depressed feelings }\end{array}$ & .68 & .19 & .10 \\
\hline RRS 11. & $\begin{array}{l}\text { Write down what I am thinking about } \\
\text { and analyze it }\end{array}$ & .67 & .10 & .05 \\
\hline RSS 10. & $\begin{array}{l}\text { Repeatedly thinking about what } \\
\text { sadness is by concentrating on } \\
\text { feelings and try to understand them }\end{array}$ & .56 & .10 & .37 \\
\hline RSS 11. & $\begin{array}{l}\text { Thinking long enough about sadness } \\
\text { will have a deeper meaning that I will } \\
\text { understand myself better }\end{array}$ & .51 & .15 & .48 \\
\hline RSS 3. & $\begin{array}{l}\text { Search my mind many times to try } \\
\text { and figure out if there is anything } \\
\text { about my personality that have led to } \\
\text { feel this way }\end{array}$ & .48 & .01 & .44 \\
\hline RRS 9. & $\begin{array}{l}\text { Think Why do I always react this } \\
\text { way? }\end{array}$ & .46 & .23 & .09 \\
\hline RRS 12. & $\begin{array}{l}\text { Think about a recent situation } \\
\text { wishing it had gone better }\end{array}$ & .31 & .24 & .16 \\
\hline RRS 20. & Listen to sad music & .27 & .10 & .20 \\
\hline RRS 14. & Think about how sad I feel & .13 & .73 & .02 \\
\hline RRS 16. & $\begin{array}{l}\text { Think about how I don't feel up to } \\
\text { doing anything }\end{array}$ & .14 & .72 & .18 \\
\hline RRS 2. & $\begin{array}{l}\text { Think I won't be able to do my job/ } \\
\text { work because I feel so badly }\end{array}$ & .01 & .70 & .08 \\
\hline RRS 5. & $\begin{array}{l}\text { Think about how passive and } \\
\text { unmotivated I feel }\end{array}$ & .15 & .68 & .11 \\
\hline RRS 8. & Think Why can't I get going? & .10 & .68 & .02 \\
\hline RRS 3. & $\begin{array}{l}\text { Think about my feelings of fatigue } \\
\text { and achiness }\end{array}$ & .06 & .67 & .03 \\
\hline RRS 4. & $\begin{array}{l}\text { Think about how hard it is to } \\
\text { concentrate }\end{array}$ & .09 & .64 & .08 \\
\hline RRS 1. & Think about how alone I feel & .16 & .60 & .09 \\
\hline RRS 15. & $\begin{array}{l}\text { Think about shortcomings, failings, } \\
\text { faults, mistakes }\end{array}$ & .05 & .56 & .25 \\
\hline RRS 19. & $\begin{array}{l}\text { Think about how angry you are with } \\
\text { yourself }\end{array}$ & .20 & .43 & .31 \\
\hline RSS 1. & $\begin{array}{l}\text { Difficulty getting myself to stop } \\
\text { thinking about how sad I am }\end{array}$ & .04 & .42 & .40 \\
\hline
\end{tabular}


Table 1 (continued)

\begin{tabular}{|c|c|c|c|c|}
\hline Item & Item description & Factor 1 & Factor 2 & Factor 3 \\
\hline RSS 8. & $\begin{array}{l}\text { If people talk or ask a question it feels } \\
\text { as though they interrupt a silent } \\
\text { conversation I have with myself } \\
\text { about my sadness }\end{array}$ & .01 & .05 & .75 \\
\hline RSS 7. & $\begin{array}{l}\text { I lie in bed and keep thinking about } \\
\text { my lack of motivation and wonder } \\
\text { whether it will ever return }\end{array}$ & .25 & .33 & .72 \\
\hline RSS 6. & $\begin{array}{l}\text { Keep wondering about how I was } \\
\text { happy at other points in life }\end{array}$ & .05 & .03 & .68 \\
\hline RSS 9. & $\begin{array}{l}\text { Wondering about meaning of life and } \\
\text { find clues that may understand } \\
\text { sadness }\end{array}$ & .27 & .02 & .66 \\
\hline RSS 5. & $\begin{array}{l}\text { Search my mind repeatedly for events } \\
\text { or experiences in childhood that may } \\
\text { help understand sad feelings }\end{array}$ & .30 & .18 & .63 \\
\hline RSS 4. & $\begin{array}{l}\text { Get absorbed in thinking about why I } \\
\text { am sad and find it difficult to think } \\
\text { about other things }\end{array}$ & .18 & .17 & .58 \\
\hline RSS 13. & $\begin{array}{l}\text { Exhausting myself by thinking about } \\
\text { myself and the reasons for my sadness }\end{array}$ & .24 & .14 & .55 \\
\hline RRS 13. & $\begin{array}{l}\text { Think Why do I have problems that } \\
\text { other people don't have? }\end{array}$ & .12 & .40 & .50 \\
\hline RSS 12. & $\begin{array}{l}\text { Thinking about problems to try and } \\
\text { examine where things went wrong }\end{array}$ & .37 & .16 & .40 \\
\hline RRS 7. & $\begin{array}{l}\text { Think about how I don't seem to feel } \\
\text { anything any more }\end{array}$ & .04 & .36 & .39 \\
\hline
\end{tabular}

Note $:$ RRS $=$ ruminative response scale; RSS $=$ rumination on sadness scale. Factor loadings on the corresponding factors are displayed in bold.

this factor, which accounted for $48 \%$ of the variance. The factor was comparable to the 'rumination on sadness' scale obtained in the joint factor analysis.

\subsection{Reliability of the rumination scales}

Internal consistency reliabilities (Cronbach $\alpha$ ) of the 'rumination on causes of sadness', the 'symptom-based rumination', and the 'rumination on sadness' scales were very good (see Table 3). Test-retest stability was assessed over the 6-month time-interval. Modest test-retest correlations were found for the 'rumination on causes of sadness' (ICC $=.43$ ), the 'symptom-based rumination' (ICC $=.53$ ) factor, and the 'rumination on sadness' factor $(\mathrm{ICC}=.53)$.

\subsection{Construct validity}

Table 3 presents a correlation matrix, depicting the associations between the rumination scales and the other self-report measures $(t=1)$. As can be seen in Table 3 , moderate Pearson correlation coefficients were found between the rumination factors and depression 
Table 2

Descriptive statistics of the questionnaire scores

\begin{tabular}{|c|c|c|c|c|}
\hline & \multicolumn{2}{|c|}{$\begin{array}{c}\text { Baseline }(t=1) \\
\quad N=331\end{array}$} & \multicolumn{2}{|c|}{$\begin{array}{c}\text { Six months }(t=2) \\
N=73\end{array}$} \\
\hline & $M$ & $\mathrm{SD}$ & $M$ & $\mathrm{SD}$ \\
\hline Rumination (causes) & 24.5 & 7.7 & 22.6 & 7.5 \\
\hline Rumination (symptoms) & 22.5 & 6.2 & 20.9 & 5.7 \\
\hline Rumination (sadness) & 27.3 & 8.8 & 24.6 & 8.0 \\
\hline Depression (Zung) & 34.5 & 6.8 & 34.2 & 6.3 \\
\hline Trait anxiety (STAI-T) & 36.0 & 9.3 & 34.9 & 8.2 \\
\hline Neuroticism (EPQ) & 4.2 & 2.9 & 3.9 & 2.8 \\
\hline Fear of spiders (FSQ) & 18.0 & 25.0 & - & - \\
\hline Aggression (AQ) & 63.3 & 12.4 & - & - \\
\hline
\end{tabular}

Note: Rumination (causes) = 'rumination on causes of sadness', Rumination (symptoms) = 'symptom-based rumination', Rumination (sadness) = 'rumination on sadness'. STAI-T = trait version of the state-trait anxiety inventory, $\mathrm{EPQ}=$ Eysenck personality questionnaire, FSQ = fear of spiders questionnaire, AQ = aggression questionnaire.

Table 3

Correlation matrix of self-report measures

\begin{tabular}{|c|c|c|c|c|}
\hline & $\begin{array}{l}\text { Rumination } \\
\text { (causes) }\end{array}$ & $\begin{array}{l}\text { Rumination } \\
\text { (symptoms) }\end{array}$ & $\begin{array}{l}\text { Rumination } \\
\text { (sadness) }\end{array}$ & $\alpha$ \\
\hline Rumination (causes) & - & & & .90 \\
\hline Rumination (symptoms) & $.68^{*}$ & - & & .87 \\
\hline Rumination (sadness) & $.80^{*}$ & $.76^{*}$ & - & .90 \\
\hline Depression (Zung) & $.27^{*}$ & $.49^{*}$ & $.47^{*}$ & .82 \\
\hline Trait anxiety (STAI-T) & $.35^{*}$ & $.49^{*}$ & $.53^{*}$ & .92 \\
\hline Neuroticism (EPQ) & $.34^{*}$ & $.53^{*}$ & $.45^{*}$ & .79 \\
\hline Fear of spiders (FSQ) & .07 & .11 & .14 & .96 \\
\hline Aggression (AQ) & .10 & $.26^{*}$ & $.26^{*}$ & .82 \\
\hline
\end{tabular}

Note: Correlations are computed on baseline data $(N=192)$ while $\alpha$ 's are computed on the total sample $(N=331)$. Rumination (causes) = 'rumination on causes of sadness', Rumination (symptoms) $=$ 'symptombased rumination', Rumination (sadness) = 'rumination on sadness'. STAI-T = trait version of the state-trait anxiety inventory, EPQ = Eysenck Personality questionnaire, FSQ = fear of spiders questionnaire, AQ = aggression questionnaire.

$* p<.01$.

(Zung), trait anxiety (STAI-T), and neuroticism (EPQ). Compared to 'rumination on causes of sadness, the 'symptom-based rumination' and 'rumination on sadness' factors were more strongly associated with depression $(Z=5.47, p<.001$ and $Z=6.22, p<.001$, respectively), anxiety $(Z=3.56, p<.001$ and $Z=5.82, p<.001$, respectively), and neuroticism $(Z=3.80, p<.001$ and $Z=3.46, p=.001$, respectively). The differences in degree of association between the rumination factors and depression, trait anxiety, and neuroticism did not reach statistical significance. Further, the rumination scales were more strongly associated with depression than with either FSQ or aggression AQ (Z's $>2.92$, $p$ 's $<.002$ ) providing support for the construct validity (i.e., discriminant validity) of the 
Table 4

Results of regression analyses predicting symptoms of depression $(t=2)$ as a function of baseline rumination and depression $(t=1)$, while controlling for gender $(N=73)$

\begin{tabular}{|c|c|c|c|c|}
\hline Model summary & Predictors & $\beta$ & SE & $p$ \\
\hline \multicolumn{5}{|l|}{ Rumination on causes of sadness } \\
\hline \multirow[t]{3}{*}{ Step 1: $R^{2}=.43, F(3,69)=19.2, p<.001$} & Rumination (causes) & .06 & .09 & .55 \\
\hline & Baseline depression & .63 & .09 & $<.001$ \\
\hline & Gender & -.16 & .09 & .09 \\
\hline Step 2: $R^{2}=.47, F(4,68)=16.9, p<.001$ & Baseline depression*Rumination (causes) & 1.54 & .64 & .02 \\
\hline \multicolumn{5}{|l|}{ Symptom-based rumination } \\
\hline \multirow[t]{3}{*}{ Step 1: $R^{2}=.43, F(3,69)=19.0, p<.001$} & Rumination (symptoms) & .02 & .11 & .88 \\
\hline & Baseline depression & .63 & .11 & $<.001$ \\
\hline & Gender & -.16 & .09 & .07 \\
\hline Step 2: $R^{2}=.42, F(4,68)=14.9, p<.001$ & Baseline depression $*$ Rumination (symptoms) & .37 & .72 & .60 \\
\hline \multicolumn{5}{|l|}{ Rumination on sadness } \\
\hline \multirow[t]{3}{*}{ Step 1: $R^{2}=.46, F(3,69)=21.1, p<.001$} & Rumination (sadness) & .20 & .11 & .07 \\
\hline & Baseline depression & .53 & .10 & $<.001$ \\
\hline & Gender & -.15 & .09 & .10 \\
\hline Step 2: $R^{2}=.45, F(4,68)=15.6, p<.001$ & Baseline depression $*$ Rumination (sadness) & .02 & .62 & .97 \\
\hline
\end{tabular}

rumination factors. Interestingly, a significant correlation was also found between the 'symptom-based rumination' and 'rumination on sadness' scales and aggression.

\subsection{Prediction of depressive symptoms}

Before conducting the linear regression analyses, normality of the dependent variables was checked as well as possible outliers (Cook's distances) and the degree of collinearity between the independent variables. There were no serious deviations from normality, no outliers, and there was no substantial collinearity between the independent variables. As may be expected, baseline depression was the best predictor of future depressive symptoms. The interaction between 'rumination on causes of sadness' and baseline depression was also predictive of future depressive symptoms (see Table 4). In clarifying this interaction, we examined simple slopes at three levels of the moderator (i.e., rumination on causes of sadness): the mean, one standard deviation below, and one standard deviation above the mean (see O'Connor, 1998). The relation between baseline depressive symptoms and future depressive symptoms was non-significant for one standard deviation below the mean, $(\beta=.28, \mathrm{SE}=.16, p=.09)$ but was significant for the mean $(\beta=.52, \mathrm{SE}=.10, p<.001)$ and for one standard deviation above the mean $(\beta=.77$, $\mathrm{SE}=.10, p<.001)$.

\section{Discussion}

The present study investigated the psychometric properties of two measures of rumination, the ruminative response scale (RRS; Nolen-Hoeksema \& Morrow, 1991) and the rumination on sadness scale (RSS; Conway et al., 2000), in a sample of undergraduates. A joint (exploratory) factor analysis on RRS and RSS scores yielded a 
three-factor model. Factors were labeled 'rumination on causes of sadness', 'symptombased rumination', and 'rumination on sadness'. It should be noted that it is unclear to what extent the 'symptom-based rumination' scale was formed due to a 'wording effect'. That is, most items from this scale share the word 'think'. Although these items appear to have a specific component of ruminative thinking in common, it cannot be ruled out that the wording of these items might have contributed to the emergence of this factor. The content of the factors obtained in the joint factor analysis showed strong resemblance to the rumination factors obtained in previous factor analytic studies (e.g., Bagby \& Parker, 2001; Cox et al., 2001; Treynor et al., 2003). Additional separate factor analyses on the RRS items and the RSS items yielded a two-factor model for the RRS, with factors largely comparable to the 'rumination on causes of sadness' and 'symptom-based rumination', and a one-factor model for the RSS, which resembled the original RSS. Surprisingly, the current study did not find evidence for gender differences on the rumination scales, which is in contrast to other studies (e.g., Mezulis, Abramson, \& Hyde, 2002). One possible explanation for the failure to find gender differences on the rumination scales might be due to the absence of gender differences on the depression measure. It has been suggested that the gender difference in rumination mediates the gender difference in depression such that the gender difference in depression becomes non-significant when controlling for gender differences in rumination (e.g., Butler \& Nolen-Hoeksema, 1994; Nolen-Hoeksema et al., 1999).

Further examination of the psychometric properties of the obtained rumination factors indicated that the internal consistency (Cronbach $\alpha$ 's) was very good. Test-retest stability over a 6-month period of time was moderate. These reliability data are largely in keeping with previous research, except for the test-retest stability, which was somewhat lower as compared to test-retest stability coefficients as found in clinical populations (see Luminet, 2004). It is possible that in non-clinical individuals, the completion of measures of rumination is influenced to a greater extent by fluctuations in current mood state than is the case with individuals who are clinically depressed.

The construct validity of the rumination scales was supported by significant although moderate associations with depression, trait anxiety, and neuroticism. Thus, rumination was not specifically related to depression but to negative affect in general. These findings are in line with previous research linking rumination to depression as well as anxiety (e.g., Nolen-Hoeksema, 2000). This raises the question as to whether rumination might be linked to general negative affectivity or neuroticism, which is thought to be a common component of anxiety and depression (see Clark \& Watson, 1991). Roberts et al. (1998) found evidence to suggest that rumination mediates the effects of neuroticism on vulnerability to depression, and this seems to indicate that rumination might reflect an important cognitive manifestation of neuroticism (see also Muris, Roelofs, Rassin, Franken \& Mayer, 2005). The correlations between the rumination scales and measures of spider fear and aggression were significantly smaller than those between the rumination scales and self-reported depression. This can be taken as evidence for the construct validity, in particular the discriminant validity, of the rumination scales. Further, 'symptom-based rumination' and 'rumination on sadness' were more strongly associated with depressive symptoms than 'rumination on causes of depression'. However, the 'symptom-based rumination' and 'rumination on sadness' scales were not differently related to depressive symptoms, suggesting that the attempt of Conway et al. (2000) to create a rumination measure with less item overlap than the RRS with measures of depression was only partly successful. It 
remains yet undetermined how much of the relation between symptom-based rumination and depressive symptoms is really due to item content overlap and how much is due to the process of rumination.

With respect to the prediction of future depression scores, scores on the 'rumination on causes of sadness' scale interacted with baseline depression scores in predicting future depression scores. More specifically, baseline levels of depressive symptoms were predictive of future depressive symptoms and this was particularly true for individuals with higher levels of 'rumination on causes of sadness'. Other studies have also shown that people who are prone to ruminate when distressed, will experience more severe and prolonged episodes of depression than non-ruminators (e.g., Just \& Alloy, 1997; Lyubomirsky \& NolenHoeksema, 1993; Nolen-Hoeksema, 1991; Nolen-Hoeksema \& Morrow, 1991), but these studies used the total score on the RRS as an index for rumination. The results of the present study suggest that at least in non-clinical individuals, there is a need to differentiate between components of rumination in rumination research.

Three limitations of the present study need to be addressed. First, given the importance of gender differences in rumination style (Nolen-Hoeksema, 1987, 1990), a limitation of the current study is that the sample size was too small to assess factorial invariance as a function of gender. Second, it should be noted that the sample was predominantly female limiting the generalizability of the results to males. Third, only a small subsample of the initial $t=1$ sample participated in the follow-up assessment and so one could argue that selection bias might have influenced the results. However, as there were no significant differences in mean rumination scores on the $t=1$ assessment between participants and non-participants, it does not seem to be the case that individuals high on rumination did not participate in the follow-up assessment. Despite these limitations, it seems increasingly clear from past research that how people respond to their mood state has an important influence on the intensity and duration of those states. Such responses can be important targets of effective psychological interventions (see for an overview Papageorgiou \& Wells, 2004). For example, strategies such as rumination-cued activation, which involves teaching depressed people to notice when they are ruminating and to use this as a cue to activate themselves (Addis \& Martell, 2004; Martell, Addis, \& Jacobson, 2001), and mindfulnessbased cognitive therapy (Segal, Williams, \& Teasdale, 2002), which has been developed as a new approach to prevent depressive relapse, may exert their effects through reducing ruminative responses. It is also important to clarify what rumination scales actually intend to measure. In this context, Siegle (2000) has argued for the urge to define the various types of rumination as it is clear that these different scales of rumination may tap different phenomena. The current study used exploratory factor analysis to examine the factor structure of two rumination questionnaires. Clearly, there is a need for confirmatory factor analysis to test the factor structure obtained in the present study as well as the other factor models outlined in the introduction. Furthermore, the utility of the obtained rumination factors warrant further investigation in clinical samples to increase our knowledge about specific aspects of rumination that may constitute a cognitive vulnerability factor to depression.

\section{References}

Addis, M. E., \& Martell, C. R. (2004). Ending depression one step at a time: The new behavioral activation approach to getting your life back. Oakland: New Harbinger. 
Bagby, R. M., \& Parker, J. D. A. (2001). Relation of rumination and distraction with neuroticism and extraversion in a sample of patients with major depression. Cognitive Therapy and Research, 25, 91-102.

Buss, A. H., \& Perry, M. (1992). The aggression questionnaire. Journal of Personality and Social Psychology, 63, 452-459.

Butler, L. D., \& Nolen-Hoeksema, S. (1994). Gender differences in responses to depressed mood in a college sample. Sex roles, 30, 331-346.

Clark, L. A., \& Watson, D. (1991). Tripartite model of anxiety and depression: Psychometric evidence and taxonomic implications. Journal of Abnormal Psychology, 100, 316-336.

Cohen, J., \& Cohen, P. (1983). Applied multiple regression/correlation analysis for the behavioral sciences. Hillsdale, New York: Lawrence Erlbaum Association.

Conway, M., Csank, P. A. R., Holm, S. L., \& Blake, C. K. (2000). On assessing individual differences in rumination on sadness. Journal of Personality and Assessment, 75, 404- 425.

Cox, B. J., Enns, M. W., \& Taylor, S. (2001). The effect of rumination as a mediator of elevated anxiety sensitivity in major depression. Cognitive Therapy and Research, 25, 525-534.

Eysenck, H. J., \& Eysenck, S. B. G. (1991). Manual of the Eysenck Personality Scales (EPS adult). London: Hodder \& Stoughton.

Just, N., \& Alloy, L. B. (1997). The response styles theory of depression: Tests and an extension of the theory. Journal of Abnormal Psychology, 106, 221-229.

Kozeny, J. (1987). Psychometric properties of the zung self-rating depression scale. Activitas Nervosa Superior, 29, $279-284$.

Kuehner, C., \& Weber, I. (1999). Responses to depression in unipolar depressed patients: An investigation of Nolen-Hoeksema's response styles theory. Psychological Medicine, 29, 1323-1333.

Lam, D., Schuck, N., Smith, N., Farmer, A., \& Checkley, S. (2003). Response style, interpersonal difficulties and social functioning in major depressive disorder. Journal of Affective Disorders, 75, 279-283.

Lam, D., Smith, S., Checkley, S., Rijsdijk, F., \& Sham, P. (2003). Effect of neuroticism, response style and information processing on depression severity in a clinically depressed sample. Psychological Medicine, 33, $469-479$.

Luminet, O. (2004). Measurement of depressive rumination and associated constructs. In: Papageorgiou, C., \& Wells, A., (Eds), Depressive rumination. Nature, theory and treatment (pp. $187-215)$. Chichester: Wiley.

Lyubomirsky, S., \& Nolen-Hoeksema, S. (1993). Self-perpetuating properties of dysphoric rumination. Journal of Personality and Social Psychology, 65, 339-349.

Martell, C. R., Addis, M. E., \& Jacobson, N. S. (2001). Depression in context: Strategies for guided action. New York: Norton.

Meesters, C. M. G., Muris, P., Bosma, H., Schouten, E., \& Beuving, S. (1996). Psychometric evaluation of the Dutch version of the aggression questionnaire. Behaviour Research and Therapy, 34, 839-843.

Mezulis, A. H., Abramson, L. Y., \& Hyde, J. S. (2002). Domain specificity of gender differences in rumination. Cognitive Therapy and Research, 16, 421-434.

Muris, P., \& Merckelbach, H. (1996). A comparison of two spider fear questionnaires. Journal of Behavioral and Experimental Psychiatry, 27, 241-244.

Muris, P., Merckelbach, H., \& De Jong, P. (1993). Verbalization and environmental cueing in thought suppression. Behaviour Research and Therapy, 38, 899-907.

Muris, P., Roelofs, J., Rassin E., Franken, I., \& Mayer, B. (2005). Mediating effects of rumination and worry on the links between neuroticism, and anxiety and depression. Personality and Individuals Differences, 39, 1105-1111.

Nolen-Hoeksema, S. (1987). Sex differences in unipolar depression: Evidence and theory. Psychological Bulletin, $101,259-282$.

Nolen-Hoeksema, S. (1990). Sex differences in depression. Stanford, CA: Stanford University Press.

Nolen-Hoeksema, S. (1991). Responses to depression and their effects on the duration of depressive episodes. Journal of Abnormal Psychology, 100, 569-582.

Nolen-Hoeksema, S. (1997). Rumination and psychological distress among bereaved partners. Journal of Personality and Social Psychology, 72, 855-862.

Nolen-Hoeksema, S. (1998). Ruminative coping with depression. In: J. Heckhausen, \& C. S. Dweck (Eds.), Motivation and self-regulation across the life span. (pp. 237-256) Cambridge: Cambridge University Press.

Nolen-Hoeksema, S. (2000). The role of rumination in depressive disorders and mixed anxiety/depressive symptoms. Journal of Abnormal Psychology, 109, 504-511. 
Nolen-Hoeksema, S., Larson, J., \& Grayson, C. (1999). Explaining the gender differences in depressive symptoms. Journal of Personality and Social Psychology, 77, 1061-1072.

Nolen-Hoeksema, S., \& Morrow, J. (1991). A prospective study of depression and posttraumatic stress symptoms after a natural disaster: The 1989 Loma Preita earthquake. Journal of Personality and Social Psychology, 61, $115-121$.

Nolen-Hoeksema, S., \& Morrow, J. (1993). Effects of rumination and distraction on naturally occurring depressed mood. Cognition and Emotion, 7, 561-570.

Nolen-Hoeksema, S., Morrow, J., \& Frederickson, B. L. (1993). Response styles and the duration of depressed mood. Journal of Abnormal Psychology, 102, 20-28.

Nolen-Hoeksema, S., Parker, L., \& Larson, J. (1994). Ruminative coping with depressed mood following loss. Journal of Personality and Social Psychology, 67, 92-104.

O'Connor, B. P. (1998). Simple: All-in-one programs for exploring interactions in moderated multiple regression. Educational and Psychological Measurement, 58, 836-840.

O'Connor, B. P. (2000). SPSS and SAS programs for determining the number of components during parallel analysis and Velicer's MAP test. Behavior Research Methods, Instruments, and Computers, 32, 396-402.

Papageorgiou, C., \& Wells, A. (2004). Depressive rumination: nature, theory and treatment (pp. 185-274). Chichester: Wiley.

Raes, F., Hermans, D., \& Eelen, P. (2003). The Dutch version of the ruminative response scale (RRS-NL) and the rumination on sadness scale (RSS-NL). Gedragstherapie, 36, 97-104.

Roberts, J. E., Gilboa, E., \& Gotlib, I. H. (1998). Ruminative response styles and vulnerability to episodes of dysphoria: Gender, neuroticism, and episode duration. Cognitive Therapy and Research, 22, 401-423.

Roelofs, J., Peters, M. L., Deutz, J., Spijker, C., \& Vlaeyen, J. W. S. (2005). The fear of pain questionnaire (FPQ): Further psychometric examination in a non-clinical sample. Pain, 116, 339-346.

Rusting, C. L., \& Nolen-Hoeksema, S. (1998). Regulating responses to anger: Effects of rumination and distraction on angry mood. Journal of Personality and Social Psychology, 77, 1073-1086.

Segal, Z. V., Williams, J. M. G., \& Teasdale, J. D. (2002). Mindfulness-based cognitive therapy for depression: A new approach to preventing relapse. New York: The Guilford Press.

Siegle, G. (2000). Convergence and divergence in measures of rumination. Presentation to the Association for the Advancement of Behavior Therapy, New Orleans, November 18, 2000.

Spielberger, C. D., Gorsuch, R. L., \& Lushene, R. E. (1970). State-trait anxiety inventory. Palo Alto: Consulting Psychologists Press.

Szymanski, J., \& O'Donohue, W. (1995). Fear of spiders questionnaire. Journal of Behaviour Therapy and Experimental Psychiatry, 26, 31-34.

Teasdale, J. D., \& Dent, J. (1987). Cognitive vulnerability to depression: An investigation of two hypotheses. British Journal of Clinical Psychology, 26, 113-126.

Treynor, W., Gonzalez, R., \& Nolen-Hoeksema, S. (2003). Rumination reconsidered: A psychometric analysis. Cognitive therapy and Research, 27, 247-259.

Wegner, D. M. (1994). Ironic processes of mental control. Psychological Review, 101, 34-52.

Wegner, D. M., Schneider, D. J., Carter, S. R., \& White, T. L. (1987). Paradoxical effects of thought suppression. Journal of Personality and Social Psychology, 53, 5-13.

Zung, W. W. K. (1965). A self-rating depression scale. Archives of General Psychiatry, 12, 63-70.

Zwick, W. R., \& Velicer, W. F. (1986). Comparison of five rules for determining the number of components to retain. Psychological Bulletin, 99, 432-442. 